\title{
Congress reports
}

(C) 2018 Fondazione Vasculab impresa sociale ONLUS. All rights reserved.

\section{SCP Post Congress Report}

\section{4th Biannual National Congress, Nov 1-3, 2019 Montreal, Qc Canada.}

P Raymond-Martimbeau ${ }^{1}$
${ }^{1}$ Vice-President, Canadian Society of Phlebology. Director, Dallas Non Invasive Vascular Laboratories. Director, Vein Institude of Texas. submitted: Jan 3, 2020, accepted: Jan 3, 2020, EPub Ahead of Print: Jan 7, 2020

Conflict of interest: none

DOI: 10.24019/jtavr.72 - Corresponding author: Dr. Pauline Raymond-Martimbeau, pmartimbo@aol.com

(C) 2018 Fondazione Vasculab impresa sociale ONLUS. All rights reserved.

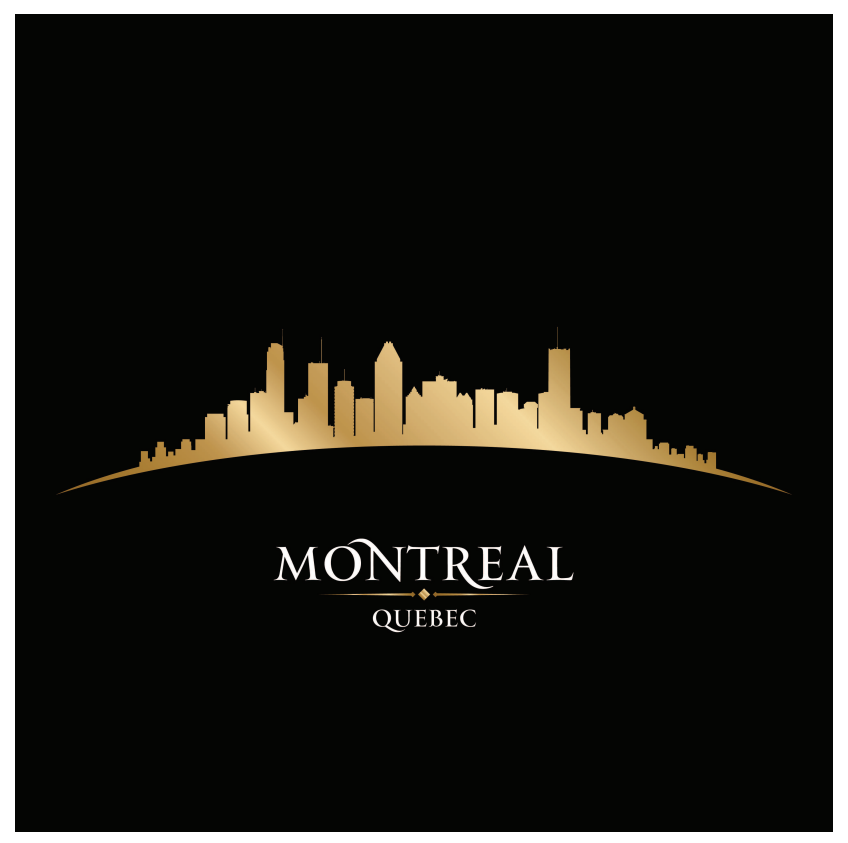

For the past 44 years, the Canadian Society of Phlebology (SCP) has been hosting a congress on chronic venous disease. The last congress took place in Montreal, Qc, Canada, November 1-3, 2019. Leading experts from all the scientific fields in phlebology got together to provide meaningful multi-faceted explorations of complex issues.

Vein care professionals participated in a threeday dynamic event. The first day, the program allowed interactive discussions and debates on curriculum topics of interest and all aspects of ultrasound- guided sclerotherapy.
Drs. Bentley, Hill, Hamel-Desnos, Wong, RaymondMartimbeau, Gianesini, Crebassa, Paradis, Zerrouk, Antignani, Cervi, Danylewick, Dupuis, Kieffer, Nadeau, St-Amour and Zummo contributed through case studies and debates to make this day a great educational experience.

The second day, delegates shared their research output and clinical experience whereas advanced issues and novel surgical and non-surgical technologies were covered. In collaboration with the vWin Foundation, an historical Pupil \& Tutor session organized by Drs Gianesini, Bentley, Serralde and Raymond-Martimbeau was very successful. Young phlebologists coached by mentors presented common research. Discussants commented on their work. An award was given to the paper: Iliocaval Recanalization for Permanent Filter-Associated Venous Thrombosis from Drs Perez-Lucas and Torres-Martinez.

Drs. Perez Lucas, Rodrigues, Sumaj, Nguyen and Esper were the young finalists for this project. The third day, the high quality of research presentations also contributed to the great success of this event.

We wish to thank the presenters, participants and industry sponsors for their ongoing commitment to education and their support which directly benefit our patients.

The SCP congress takes place twice a year, in the Fall in the East part of Canada and in the Spring in the West part. Each time, a multidisciplinary Canadian and International faculty mingle together, both researchers and clinicians to offer a global vision of phlebology and create knowledge exchange for better patient care. 

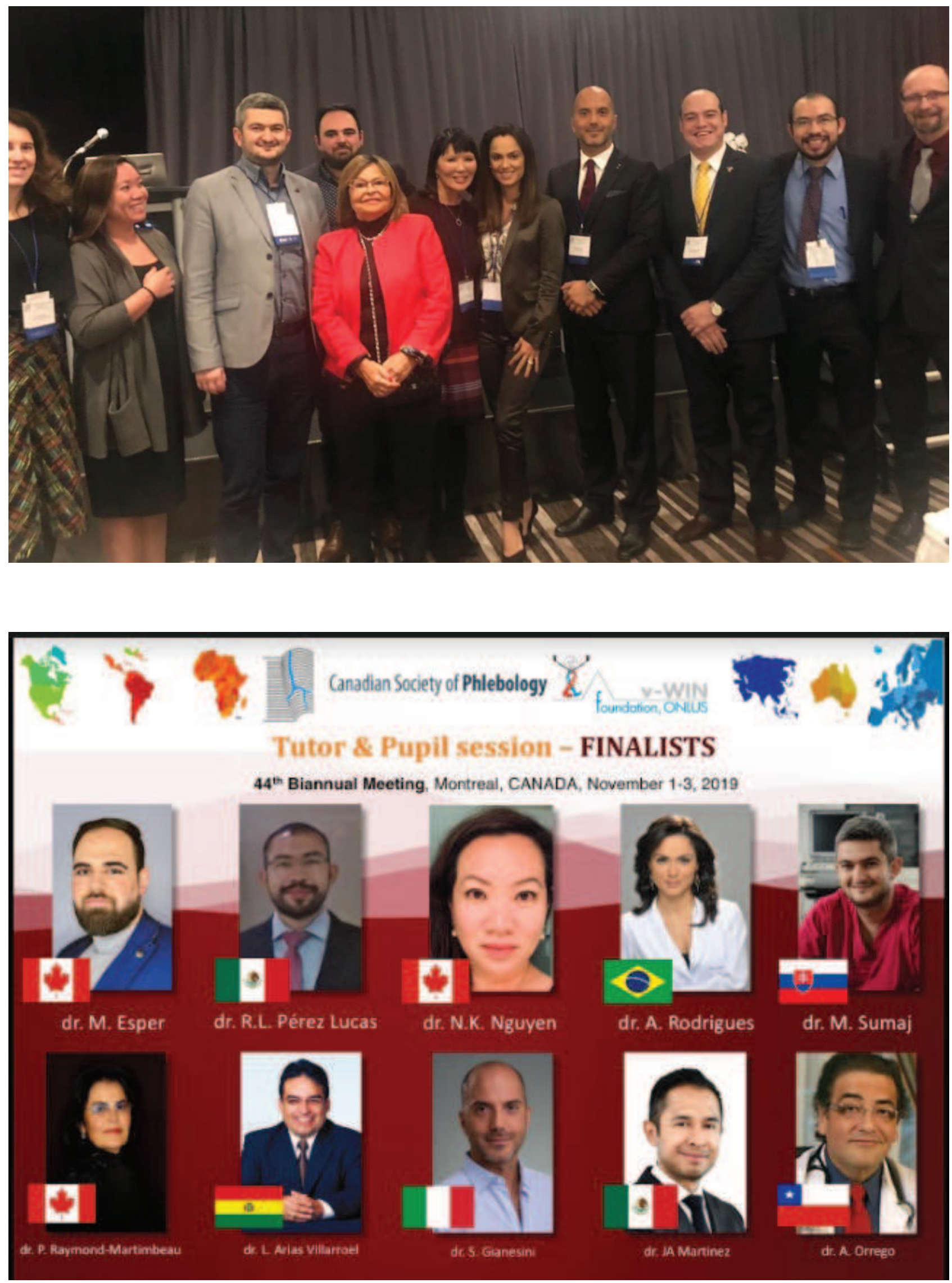
The next congress will be held in Vancouver, BC, Canada on 25-26 April 2020. The highlights will be: pelvic venous disease, interactive case studies, and discussion of original papers. Physicians from different disciplines will be sharing the same vision and educational purpose.
We are looking forward to welcoming you to Canada,

Pauline Raymond-Martimbeau, MD, FAVLS, DABVLM

Vice-President, Canadian Society of Phlebology

Director, Dallas Non Invasive Vascular Laboratories

Director, Vein Institude of Texas

\section{National Congress of the Italian Society for Vascular Investigations}

SIDV - Rome May 3-5, 2019

\section{Aluigi ${ }^{1}$}

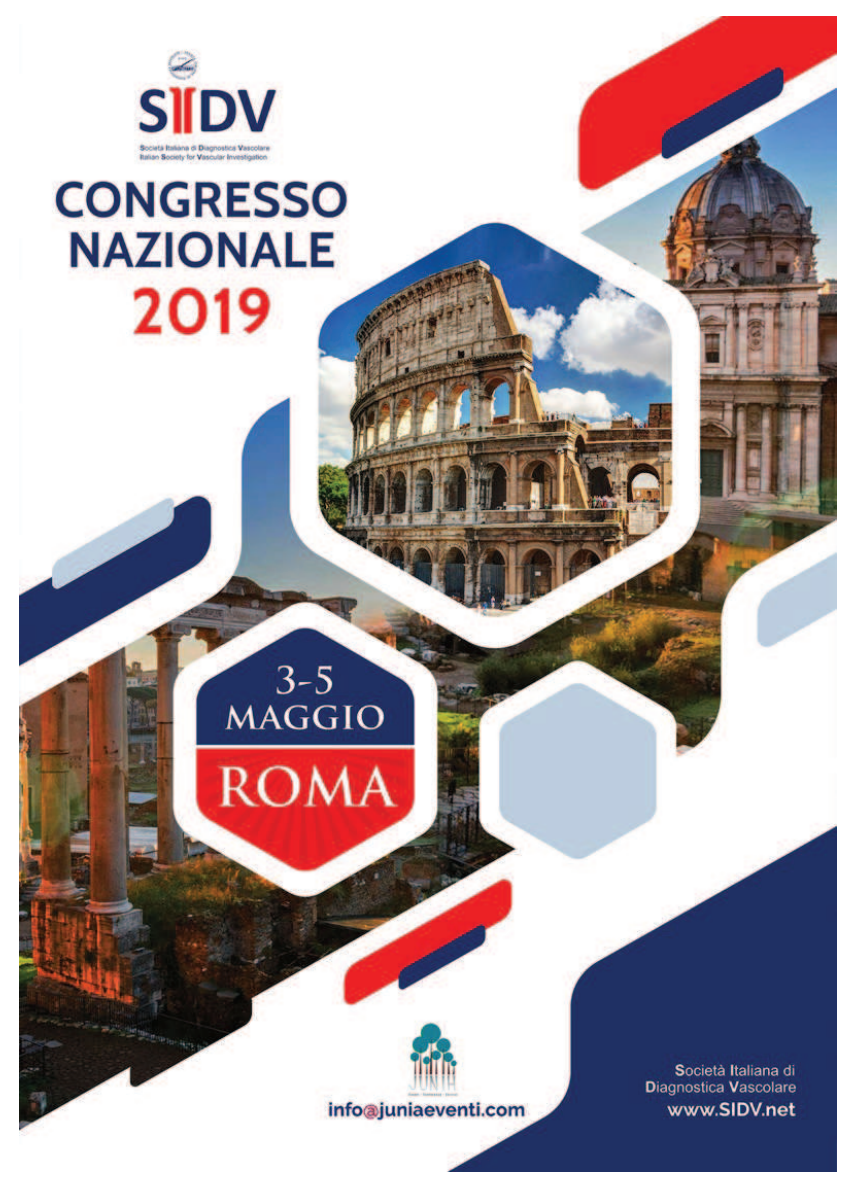

The event, arrived to its 36th edition, represents the national appointment that takes place every three years in Rome and brings together eminent national
${ }^{1}$ President of Italian Society for Vascular Investigations (SIDV) submitted: Jul 1, 2019, accepted: Jul 1, 2019, EPub Ahead of Print: Oct 1, 2019

Conflict of interest: none

DOI: 10.24019/jtavr.66 - Corresponding author: Dr. Leonardo Aluigi, 1.aluigi@libero.it

(C) 2018 Fondazione Vasculab impresa sociale ONLUS. All rights reserved.

and international personalities in the world of Vascular Medicine, Vascular Surgery and research, to address issues of general interest concerning vascular pathology and to discuss, particularly, what's new in vascular diagnostics that technology makes available for increasing accurate clinical-therapeutic pathways.

The scientific committee has established as main topics what is usually done in diagnostic terms during surgical procedures and on what must be done in the control of the same and in the follow up of the performed procedures, both in the arterial and venous field, given the many possibilities, especially in phlebology, to deal with the same pathological condition with different methods.

If it is true that vascular diagnostics is the true company mission, it is also true that only knowledge and competence in vascular medicine can allow the correct application of technological advanced diagnostic methods: the "transversality" of vascular diagnostics cannot therefore ignore the deep clinical knowledge of the treated pathologies as well as the knowledge of the intervention procedures to allow an adequate verification of the results of the therapeutic acts.

After a pre-congress moment traditionally dedicated to training through theoretical and practical courses concerning a "vascular pathway in phlebo-lymphatic pathology" and a "vascular pathway in arterial pathology", the congress has been opened with a session dedicated to technological updating. Other sessions was on "chronic venous disease", "trophic lesions" and "venous thromboembolism" discussing the methodology and diagnostic technique, pointing on the difficulties for a 
correct post-procedural or post therapeutical diagnosic evaluation.

The second part of the congress was dedicated to a theme often forgotten but of fundamental importance such as "diagnostics in the operating theater" with particular regard to: technology at the service of quality control in the operating room of vascular surgery and the modern aortic center. Large space has been devoted to the management of carotid, aortic pathology and arterial pathology of the lower limbs.
The high scientific level of the speakers and the presented reports have guaranteed the excellent success of the event with great satisfaction of the faculty and the numerous participants.

Prof. Leonardo Aluigi

President

Italian Society for Vascular Investigations (SIDV) 